\title{
The Role of Leadership in Management of Maternal Health Service in Kagera Region, Tanzania
}

\author{
Article by James Barongo Bashweka \\ Ph.D, Public Health, Texila American University, Bukoba, Tanzania \\ Email: jbarongo2004@yahoo.co.uk
}

\begin{abstract}
This paper is about the role of leadership for effective management of maternal health in Kagera Region Tanzania. Maternal health leadership is a very important component in the entire Maternal and child health (MCH) Programme and its smooth running depend on leadership capacities in management of services. In Kagera region it was claimed that leadership gaps contribute to low user rate of maternal health services that lead to high maternal mortality. However, its role in management, success and challenges in the overall programme has not been explored. Therefore, this paper is detailing about findings on what extent to which leadership is responsible for ensuring effective maternal health delivery.

Method: Study design was an exploratory qualitative approach that employed in-depth interviews. Interviews involved formal health leaders who are involved in maternal health services including: Regional Health Management (RHMT) members and Council Health Managing Team (CHMT) members who were considered to be information rich cases. Ethical consideration was attained through approval from Texila American University and seeking permission from Tanzania Government authority. Participation was voluntary whereby informed consent from participants was sought and adherence to confidentiality.

Result: Coding and analysis of results on self-competencies revealed Professionalism, Ethic, Selfreflection, critical thinking, developing others through teaching, developing others through mentoring, interdisciplinary team building and negotiation. Leadership competences in relation to wider community revealed; working with community, working with systems, policy adherence and policy advocacy. It was found out that respondents have high level of understanding in working with community, policy adherence and working with system. However, it was observed that; respondents lacked awareness and recognition, ethics, self-reflection, critical thinking and less aware on developing others through mentoring, interdisciplinary team building and negotiation.

Conclusion: Basing of the above finding it is concluded that leadership play a major role in the management of maternal health services. Recommendations were put forward including to increase understanding about maternal health leadership competence in MCH programme with more emphasis on interdisciplinary team building, negotiation, and capacity, policy advocacy practices which were not recognized by respondents and improve understanding on all identified weakness.
\end{abstract}

Keywords: Role, Leadership, maternal health, management, Kagera region, Tanzania.

\section{Background information}

Maternal health leadership capacity is a very important component in the entire maternal health programme for effective running and management of maternal health care. Maternal health leadership is about "self-leadership" for maternal health leaders, "others/ staff/ maternal health work force ,the organization and the community in which the leader operates (Maternal health leadership competence (2009).It is for this matter that the leadership was considered under in terms of those four dimensions. In this article the author will concentrate on leadership capacity in management of maternal health care in Kagera Region Tanzania in terms of self, others and to wide community. Maternal health is defined as health of women during pregnancy, childbirth and postpartum period within 42 days of termination of 
DOI: $10.21522 / \mathrm{TIJPH} .2013 .05 .04 . A r t 044$

ISSN: $2520-3134$

pregnancy (WHO, 2014). It was included in the seventh Primary Health Care (PHC) elements of Alma declaration, Health for All by 2000 (World Health Organization, 1978). PHC maternal health targets were not achieved because of various reasons including leadership gaps (Werner, 1995). Later Primary Health Care was replaced by Health Sector Reform (HSR) to strengthen health leadership. This process aimed at introducing substantive change in health structures and functions in the sector for promotion of equity (The United republic of Tanzania, Ministry of health, 2003). Health sector reform also faced leadership challenges due to failure to set clear indicators for its impact, equity, efficiency, effectiveness, quality, sustainability, social participation and evaluating tools in the overall performance such as Maternal Mortality Rate (Murillo \& Pedroza, 2002). The Health reformed was complemented by Millennium Development Goals (MDGs) particularly goal number $4 \& 5$ which targeted for improvement of maternal health and reduction Maternal Mortality Rate by increasing of Antenatal care coverage. Currently, Maternal health have been incorporated under sustainable Development plan 2030 Goals and Goal 3(3.1) which is targeting to reduce maternal mortality rate to less than 70 per 100, 000 live births (UNDP, 2014)

Kagera Region, Tanzania, Health Management Team reported low user rate of maternal health services among mothers of child bearing age (15-45) years (RHMT, 2015). For instance, there is low user rate of maternal health services that remained persistently lower as one of key factors for high Maternal Mortality Rate of 109/100,000live birth. Despite of applied strategies in managing maternal health in Kagera region the rate of decrease for maternal deaths has been too slow this may lead to failure maternal Sustainable Development Goal (MGD) which is target to reduce maternal mortality by $7.3 \%$ and reach at 70/100,000 live birth by 2030 (RHMT,2015).

Moreover, leadership strategies in management of maternal health services and extent to which leadership play part in addressing maternal health problems remains not documented. Which indicate that there is a limited understanding on how leadership plays a role in maternal health management. The researcher felt that past and current maternal health leadership strategies in maternal health management failed to address underlying factors for maternal deaths. This has triggered the minds of researcher to engage in this study with the following objectives:

To determine the health system leadership capacity in management of maternal health care in Kagera region

\section{Question to be answered is}

What are capacities of maternal health leadership in order effect managing maternal health services?

\section{Justification}

There are information and knowledge gaps on the role played by leadership strategies in managing maternal health problems in Kagera region. This continued to exist despite past and current interventions to improve maternal health. The implication for this problem and its consequences would be an increase of poor maternal health indictors in Kagera region. Therefore; this study was proposed to increasing deeper understanding on the role of leadership in maternal health service management and their gaps in the region. It anticipated that this create new thinking and planning of improved leadership strategies in order to improve current challenges. This will ultimately contribute to the reduction of MMR and improvement of maternal health in Kagera region. Furthermore, the thesis created an understanding and knowledge on the leadership strategic role in managing maternal health. It is expected that results and recommendations of this thesis will be used by the health authorities and other health stakeholders in Kagera region and Tanzania to improve the health of mothers

\section{Information about kagera region}

Kagera Region is one of the 24 regions in the United Republic of Tanzania. It lies in the North West corner of the country, along the shores of Lake Victoria with total area of 39,627 $\mathrm{km}^{2}$ comprising 28,388 $\mathrm{km}^{2}$ of land and $11,239 \mathrm{~km}^{2}$ of water. The Region is located between $1-3^{\circ}$ South of the Equator, at a longitude of $30-32^{\circ}$ east of Greenwich. It lies at an altitude of 1100-1800 meters above sea level with 
equatorial climate. The Region is sub-divided in eights (8) districts. Based on National Bureau of Statistics (NBS) 2012 region had a population of 2,458,023. Demographically with household size of 4.8, average, fertility rate of 7.3 and growth rate is 3.2. The Life expectancy at birth for men is 51years and for women 52 years as per World Data Atlas, 2012 as cited by the RHMT of Kagera region 2015.

Health services are decentralized at a District Council level and overseen by Regional Secretariat and Regional Health Management Team at region level. At the district level there is a Council Health Management Team responsible for developing and implementing yearly Comprehensive Council Health Plans (CCHP) with its counterparts at wards level the Ward Development Committees (WDC) and the Village development committees (VDC). These committees are grassroots development teams responsible for organizing and implementing all health and development plan. Regional Secretariat and Region health Management Team (RS\&RHMT) is a link between the Council Health Management Team (CHMT) and Ministry of Health and Social welfare MOHSW by ensuring development and implementation of Comprehensive Council Health Plans (CCHP) (Tanzania Ministry of Health and Prime Minister's Office, 2008).

Though people access health services preventive health are inadequate due to various factors such as shortage of resources, low community involvement and participation as the result community members suffer diseases which could be otherwise prevented through their involvement and participation (Kagera Region RS\& RHMT, 2015). Community members are not heterogonous due to existence of different tribes with different cultures and beliefs that influence health behaviors, illness behaviors and sick role health care role and health seeking behaviors for health care utilization.

Economic activities included small scale farming, for both food and cash crops, fishing, livestock keeping, mining, retail business and very few are employed. Per-capita income is Tshs. 718,901 per year in (about \$ 1.2 per day per person) with high level of poverty according to NBS (2013) poverty ranking. Low income is one of the factors for underutilization of health services in case people are supposed to pay cost sharing, mandatory user fee contribution or transport costs (RHMT, 2015). The literacy rate is estimated at $69.1 \%$ for males and $67.6 \%$ for women. There are disparities in the accessibility of essential services such safe water, sanitation, transportations between urban and rural populations. Gender inequality is among the health challenging problems with high reported care of gender based violence. This social pathology was claimed to be among the contributing factors for low accessibility of maternal health services (RS \& RHMT 2015).

\section{Maternal health legislative framework in tanzania}

Since independence in 1961, maternal health services have been a priority of Tanzania Government through safe motherhood initiative of 1974) and integration of contraceptive Pills for child spacing programme under maternal and child health services (Shija et al. 2011). Family Health International 2007 as cited by Shija et al. (2011), proclaimed that Tanzania was then first country in Sub-Saharan Africa to adopt safe motherhood initiatives in 1989 followed by the nation population policy of 1992 strategic plan on reproductive health and child survival (1997-2001) aiming at reducing maternal mortality by $50 \%$ by the year 2001. In 2008 launched another strategic plan to accelerate reduction of maternal new born. Child health was developed as one of the key tools in Antenatal Care Service provision.

Currently Maternal health has been one of six Tanzania Government's initiatives under Big Results Now (BRN) in the health sector. Big Results Now (BRN) is a services Delivery Methodology adopted by the Government of Tanzania to transform her public service delivery to achieve its Development Vision 2025 aspirations. BRN Maternal Health targets a reduction of maternal mortality Ratio from 453 to 291 per 100,000 live births, utilizing community based maternal health to improve Reproductive Maternal New born and Child Health awareness to $100 \%$ at community level by the year 2017 to 2018 . Additionally, BRN advocate for establishment of blood donors and provision of safe blood to needy pregnant mothers by $100 \%$ and increase childbirth by skilled birth attendant to $80 \%$ (BRN Health care Lab, 2014). This Priotised Maternal New born and Child Health in Tanzania and integrated it in "The 
DOI: $10.21522 / \mathrm{TIJPH} .2013 .05 .04 . A r t 044$

ISSN: $2520-3134$

Sharpened One Plan aiming at reducing Maternal and New born, children of under five deaths. (Tanzania MCH National Road Map Strategic Plan, 2008-2015).

The National Road Map Strategic Plan outlined $\mathrm{MCH}$ roles of each level from health facility community to Nation Level as it is shown under table 1 below:

Table 1. Maternal health lead health leadership structures and role from nation to ward level

The Ministry of Health and Community development, Gender, Elderly and Child welfare. CHMTs) responsible for developing and implementing yearly comprehensive health Plans.

- policies

- Resources (approved budget

- Resources requires skilled staff

Regional secretariat (RS) and Region Health Management Team RHMT lead by Regional Medical Officers

- To provide technical support for planning and implementation of the integrated Maternal Health activities in the Comprehensive Council Health Plans (CCHP)

- Coordinate, monitor and supervise maternal health activities in the region

- Technical support for training and ensuring quality in services provision

- Support district in analysis and utilization of maternal health data and disseminate report to the nation level

\section{District Health Management Team led by District Medical Officers (DMOs) Under District} Executive Directors (DED)

- Disseminate Strategic Plan to all stakeholders in the District Council including NGOs, FBOs and other private sector partners.

- Incorporate Maternal health activities into the CCHPs

- Coordinate and supervise all Maternal health activities planned and implemented by all stakeholders in the District

- Provide technical support for quality Maternal health services

- Capacity development for facility and community Maternal health interventions

- Follow up maternal death reviews at heath facility (dispensaries, health centers, district hospitals, regional hospitals, as well as voluntary agencies and private hospitals) and community levels.

- Council management teams and District Health Boards to ensure adequate resources allocation for implementation and monitoring of the maternal intervention

The Role of health facilities (Dispensary, Health Centre and Hospital) leaders

- Incorporate maternal health activities into facility health plans.

- Provide quality Maternal services

- Implement quality improvement approaches such as Quality improvement and Recognition Initiative (QIRI), pay for performance, integrated Management Cascade and collaborative Approach

- Ensure timely availability of essential equipment, supplies and drugs for service Maternal services provision

- Conduct maternal, perinatal, neonatal and child death reviews, involving the community

- Health facility committees to monitor and ensure quality Maternal service provision

- Provide technical and supportive supervision to community interventions

The role of Community (wards Development committees, Village Development Committees / Health Facility committees

- Facilitate development and monitoring of Community Maternal action plans

- Mobilize the community to participate in community interventions

- Establish and/or strengthen Community Based Maternal Information System

- Leverage community resources for the implementation of maternal interventions 


\section{Methodology}

\section{Research design}

The design was an exploratory descriptive case study that aimed at understanding the role of leadership in management of maternal health services in Kagera region, Tanzania. Qualitative approach was adapted whereby in-depth interviews were used to collect primary data. Qualitative approach was preferred because enable the understanding of the respondents' awareness and knowledge about the role played by health leaders in maternal health services management based on their own experience. Advantages of qualitative research methods are described by Edward (2008) that they are useful in capturing original information from the source; and that are useful in social science studies because they draw on the research participants' perceptions through an exploration of their knowledge, values and beliefs in relation to researched issue.

\section{Study population}

The study population was members of RHMT of Kagera Region and three CHMTs of Bukoba Municipal, Bukoba and Misenyi districts who are responsible for maternal health services. Key informants were selected based on their job description in connection to maternal health. They are considered homogenous in this study as they share roles and responsibilities, were all known as maternal health leaders in this thesis.

\section{Sampling procedure and Sample size}

Kagera region has been sampled from 21 regions in Tanzania as the Case study. Moreover, the researcher is from the area. Therefore conveniences have also been considered in the selection of study area. In terms of health structure including provision of maternal health services and leadership are the same all over the country. In Addition, Kagera region 3 districts were selected in this case study. Purposeful sampling was used to select information rich case. The reason behind for using purposeful sampling is based on information rich cases for In-depth interviews. Information rich cases are those cases that are considered under this study to have been involved in the implementation of maternal health services or responsible in administration of health care including maternal health. This sample is extreme or deviant case whose study illuminated the question under the study basing on the experiences (Patton, M .1990). Through proposed purposeful sampling, respondents were contacted from each CHMT and RHMT in order to participate in in-depth interviews. Their selection was based on their experience in dealing with maternal health for at least 3 to five years.

\section{Information needed and instrument for data collection}

As the nature of the study, qualitative data was collected from primary source through in-depth interviews and tools included a question guide. These tools were translated in Kiswahili which is the national and official language of Tanzania. Kiswahili and English were used throughout the discussion with the respondents to clarify issues. This did not cause any problem English because respondents are used with both languages in their routine work. Tools were pre-tested before their utilization in the field study to ensure their correctness and challenges were addressed accordingly.

\section{Data analysis}

Qualitative data analysis was analyzed by the use of QDA Miner Lite. This software provided a flexible, simple and comprehensive structure for managing qualitative data in key research topic, categories and themes and allowed for easy manipulation, analysis and exploration of data and results. This used two components which are components and nodes whereby documents be placed in text file and materials containing interviews transcripts and field notes. Word processor was first created into QDA Miner Lite created code and referred them to topic, categories or variables for analysis. Contents of in depth interview were read, coded and stored in Rawfile systems of software and documents This 
DOI: $10.21522 / \mathrm{TIJPH} .2013 .05 .04 . A r t 044$

ISSN: $2520-3134$

enabled the researcher to conduct as systemic analysis of data and minimized temptation fixating on particular interesting cases.

\section{Research rigor}

Rigor is addressing research constraints and maintaining consistency with predefined parameters by applying credibility, transferability generalizability, dependability reliability; and conformability. (Krefting, 1991)Therefore, the following measures were followed to achieve rigor in this study (Shenton, 2004).Credibility was achieved through consultation with authorities in relation to research goal, objectives and concept. Peer debriefing was done by exposing tools to guider and other researchers and finally were pre-tested (Shenton, 2004). The researcher administered research tools himself and used same assistants throughout the research period. Principles of rigor in qualitative research including good listening, detailed notes taking, observation and interpretation of non-verbal communication, timely documentation of data were applied. The use of QDA Miner Lite software enhanced easy analysis and interpretation of data. Though in qualitative perspective transferability and generalizability of findings from study are criticized, this case study in Kagera region represented other region in Tanzania. Moreover, all regions are utilizing the same maternal health policies, guideline through the Government of Tanzania. Therefore, possibility of transferability was attained through accuracy of representation of selected respondents from health leadership teams (Shenton, 2004). To ensure dependability of results, the researcher demonstrated and applied principles and practices in qualitative research which are good interviewing (Liamputtong and Ezzy, 2005).These principles included good communication, proper consultation, clarifying purpose and expectation of study. Moreover, data was accurately collected and documented followed by appraisal to evaluate how research was to be accomplishing plans per schedule (Shenton, 2004).

\section{Ethical consideration}

The researcher secures permission from relevant authorities prior to undertaking the research. The clearance from the Texila American University was sought and permission was also acquired from the Regional Administrative Secretary of Kagera. Participation in the study was voluntary and consent was signed by individuals who participated in the study. Individual responses and views were respected and all participants were assured of confidentiality and anonymity by not linking the data to the person's name or other identification such as his/her address. In addition, completed data was only be kept by the researcher in safe custody and tools were destroyed after they have been used for the intended purpose. Respondents were provided with letters in explaining the nature of the study, requesting their voluntary participation and assuring them about confidentiality. Consent form and other tools were translated in Kiswahili and each participant was provided with a copy to sign as a proof of their willingness to participate. It was made clear to the respondents that their participation is voluntary and that they have the right to refuse to participate in the research or withdraw from the study any time with no implications. The researcher will ask for permission to document during discussions. According to the nature of the research participants were assured that the research has no harm to them. To support the research process length time was spent informing respondents on the approach to data collection, why the research is being conducted and its usefulness. The researcher also respected social and cultural norms through consultation from leaders and during the whole period of study.

\section{Limitations}

In consideration of study are quantitative oriented research might question the small sample size used in this study, but this qualitative research was undertaken to information rich cases until saturation of information collected was reached. In addition, the study was not looking for representation but meant for deepen understanding on understating of respondent on the role of leadership in maternal health management. The researcher being familiar in the region is an advantage in many respects at the same time it could be a limiting factor if it hinders openness among the respondents. However, by ensuring 
confidentiality and giving proper explanation to the respondents about the usefulness of the research, this limitation was omitted

\section{Results}

The exploration on the role of leadership capacities in the management of maternal health services in Kagera Region was concerned with the "self-leadership" "others/ staff," the organization and the community in which the leader operates (Maternal health leadership competence (2009). It is for this matter that the leadership was to be considered under this thesis in terms of those four dimensions. They were further considered in form of strength, weakness, opportunities limitation [threat] during in-depth interviews with Council Health Management Team and Regional Health Maternal Team leaders as were revealed. In this paper, the author will concentrate on objective one of this thesis on leadership capacity in management of maternal health care in Kagera Region Tanzania.

\section{Maternal health leadership awareness and relevance of the study topic Meaning of terms}

\section{Who is maternal health leader?}

Maternal health leaders is one who understands and support MCH values, Mission and goal with sense of purpose and moral commitments. He/she values interdisciplinary collaboration and diversity and brings the capacity to think critically about $\mathrm{MCH}$ issues at both the population and individual level as well as to communicate and work with others and use self-reflection (Maternal health and child health leadership competence, 2009).

Self-leadership is attained through reading instruction, reflection and planning and serendipitous experience. This is whereby individuals increasing learning to direct their actions and growth towards specific issues of challenge in order to achieve desired goal.

Leadership in relation to "Others" is when a leader extent it to co -worker, colleague, fellow and other practitioners. This is about how a leader in maternal health and other public health field affected the lives of targeted group through a Multidisciplinary team.

Leadership in a "Wider community" is a circumstance in which a leader extends it to a broader impact on entire organization system or general mode of practice. In order to be effective, impact/ influence positive change, there is required additional skill and broader based understand of the community change process and factors that work to bring change overtime.

A wider community concept is achieved through understanding and mobilizing communities to improve the local system of health care for pregnant mothers, influence policy at state to improve availability of resources such as reimbursement of $\mathrm{MCH}$ providers and understanding that leadership is developed through learning and experience (Maternal and Child Health Leadership Competence, 2009).

Maternal health team /work force: is the team that provides or assists the support of provision for maternal and child health services and including: Maternal and child health nurses, coordinators, team leaders, clerical and others maternal health and child health workers of declines other than health staff involved in the delivery of the services and management of maternal health (Victorian Maternal and Child health Services, 2009).

During in-depth interview it was deemed important to find out whether respondents were knowledgeable about leadership capacity. It was revealed that to some extent respondents are knowledgeable on the study topic "maternal health leadership in management maternal health". Most of them commented that is interesting topic because it focusing on important health component and intend to contribute towards improvement of mother health.

"The title is very good topic since leadership is something one cannot do without with it"

"Leadership is the source of resources and organization development" 
DOI: $10.21522 / \mathrm{TIJPH} .2013 .05 .04 . A r t 044$

ISSN: $2520-3134$

"The topic is useful and interesting because leadership play a vital role in all issues related to maternal health ranging from planning and availability of resources needed to provide care" (Some of In-depth interview respondents).

The researcher also probed from respondent about whether were familiar with the terminology of leadership capacity/ competent in $\mathrm{MCH}$. Most of them were doubting concerning the way of improving their capacity. They frequently mentioned that are used to read maternal health documents, attending meetings, conduct supervision, utilizing guidelines, policies and Standard Operating Procedures (SOPs) as the way of building their leadership capacity. All of respondents missed reading of academic papers and international guideline such as Sustainable Development Goal on maternal health targets, this indicate that possibly only they are used to utilize readymade documents. This kind of self-awareness cannot motivate to strategically in addressing real needs in maternal health. The same challenge was pointed out by UNDP (2015) that, though countries are committed to universal access to sexual and reproductive health care services, still there are many gap such as weak health system in least developed countries, inaccessibility of affordable services such as medicine, contraceptives/ family planning methods and other ANC services due to leadership gaps.

It can therefore be observed that though respondents have ideas about what leadership capacity some qualities are missing as they have limited capacity in core knowledge of $\mathrm{MCH}$ population needs and not continually seeking new knowledge in order to improve their abilities and skills to effect evidence based leadership. This was argues maternal health leadership confidence group (2009) that MCH leaders should be committed to sustaining an infrastructure to recruit, train and mentor staff. The authors also asserted that leadership initiatives should improve wellbeing of tomorrow's children and families and responsible to cope with changing political, social, scientific, demographic context effectively. Hawkins et al, (2005) suggested a leader to apply Human Right Based Approach (HRBA) analysis in maternal leadership in order to advocate application of laws and policies which fulfils women's right to health; prioritizes right to maternal health in policy and national resources allocation and prioritizes right to maternal health.

\section{Self-competencies}

Self-competence components were coded in terms of maternal health knowledge, self-reflection capacity, ethics, and professionalism and critical thinking. The following graph (1) indicates coded items whereby professionalism is leading followed by knowledge on maternal health services. Though ethics was the third mentioned it scored lower followed by self-reflection and critical thinking which scored extremely lower. This may mean that respondent have high level of knowledge on maternal health and professionalism. Surprisingly, it was found out that respondents had low understanding on self-reflection, critical thanking and ethics and shown below. 


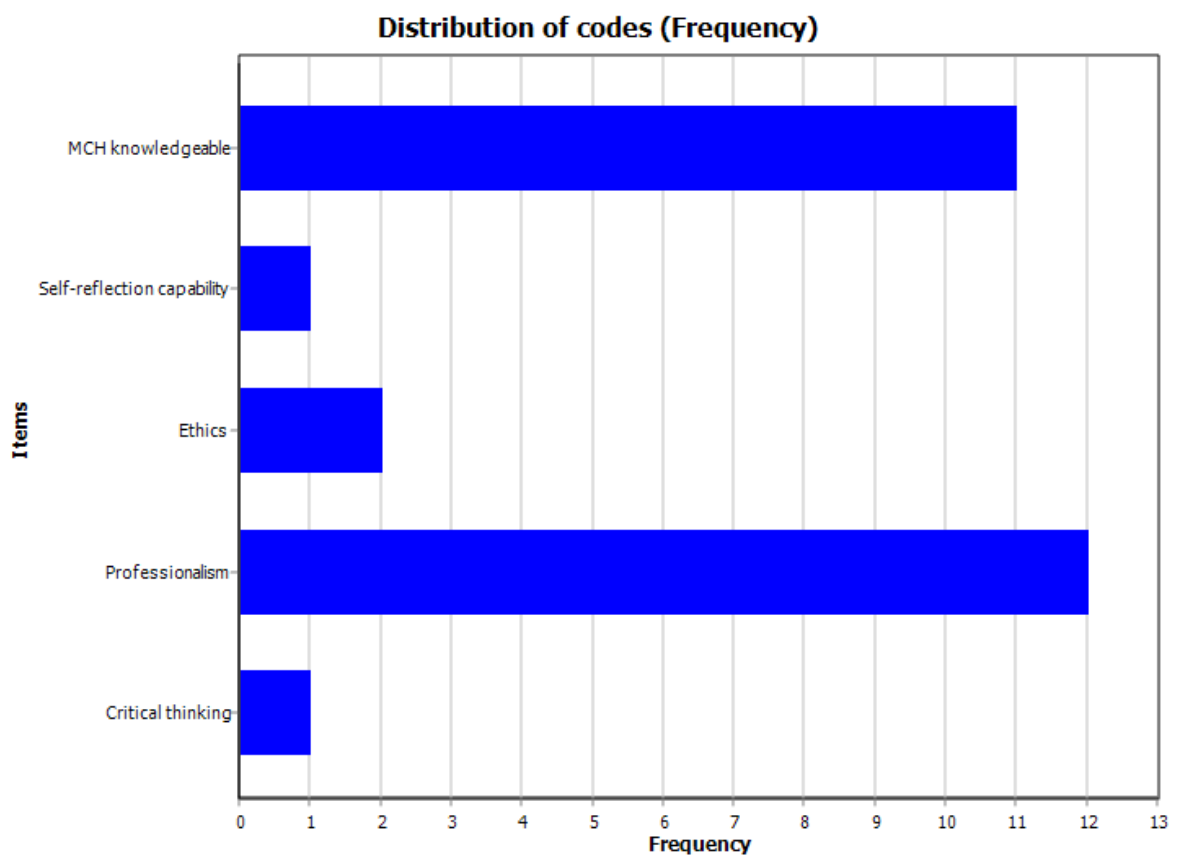

\section{Professionalism}

The Association of Schools of Public health in their undated (manual) defined professionalism as an ability to demonstrate ethical code, values and practices in making and commit to practice of personal and professional values. It was further viewed by authors that multiple public health challenges including emerging and re-emerging diseases, lack of workable health promotion and friendly policies, widening of gap between rich and poor has prompted prioritization of professionalism. It was further stressed by authors that professionals have to ask themselves "What is the right thing to do? In making decision that will affect public health. Through in-depth interview respondents were aware about maternal health leadership competence but most of them were not sure about the terminology. It found out that leaders keep up to date by reading, report guidelines, attend meetings, seeking information from knowledgeable and technical people. Some of respondents were convinced that they have capacity due to availability of qualified team of staff that conduct supervision and work under team spirit. Moreover professionalism was noted to be practiced during monitoring and evaluation, supportive supervision, follow and regular visits to health facilities. Since professionalism was an item which was leading it show that respondent consider this practice as an important one.

\section{Ethic}

Center of Health and Human Services/ centers for Disease control and prevention (CDC), (2012) define ethics as a branch of Philosophy which deals with values pertaining to human conduct considering the rightness and wrongness of action and goodness or badness of motive and ends of such action. Moreover, various Medical and Nursing dictionaries define Medical \& Nursing ethics as values and guidelines governing decision in medical practice, these are values, principle that guide a professional and ethics of decision made within the proposal.

From in-depth coded issues, ethics was less mentioned by respondents as shown in the graph no1. Some respondent who mentioned about it was said to provide terms of discussion with fellow staff in order to facilitate ethical approach and ensure improved mothers and child health services. One of respondent commented that

"Ethical and code of conduct among the staff is currently stressed due nature of existing Government which insist on ethics and integrity" 
DOI: $10.21522 / \mathrm{TIJPH} .2013 .05 .04 . A r t 044$

ISSN: $2520-3134$

Some of respondents also criticised development partners who introduce/ impose new maternal health interventions which insist mainly on for seminars for staff, a lot reporting tools without addressing ethics. Therefore, suggested to include training on ethics and maternal health good practices which will improve the challenge of staff misconduct.

From above facts, it can be discussed that unethical and misconduct maternal health providers are among the contributing factors for underutilization of maternal health services and consequentially maternal deaths. This reported by Fagbamigbe (2014) in Nigeria found that health providers were hurdle to ANC utilization due to unfriendly, and lack of accountability which was support RHMT in Kagera region that discrimination from health professionals predisposed $42 \%$ of mothers to deliver at homes (RHMT,2015).

\section{Self-reflection}

Self-reflection is the process of examining the impact of the personal values, briefs, styles of communication and experiences. This process develops deeper understanding of one's culture, personal and cultural biases, experiences and beliefs which influence future action and learning. Self-reflection is a process that can be used to maximize personal satisfaction and strengthen on $\mathrm{MCH}$ commitment (Maternal and child health leadership competence, 2009). Through this study it was learnt that reflection as a part of maternal health leadership element is rarely practiced. Respondents reported that they reflect through District Health Information Management System version2 data review, facility meetings, and annual planning meetings in which issues are discussed.

"I build capacity of my fellows' junior staff through mentorships, supervision, provision of guidelines, standard Operating Procedures (SOP) and continuing education

"I am used to read and communicate with others to gain much experience on maternal health"

"I am not a medical personal but health economist but I participate in planning and budgeting during planning and is where I apply my leadership expertise"

(Some of respondents from in-depth interviews)

Some only mentioned that keep update by reading different books and guidelines. Though to some extent reflection is practiced there is a lack of understanding about what is self-reflection. Being important aspect in maternal health there is a need improve reflection secessions on individual and group level.

\section{Critical thinking}

Critical thinking is defined as a reasonable reflective thinking focusing on deciding what to believe or do Ennis (1993) as cited by Jenkins \& Cutchens (2011).It was further explained that this is the ability to deal with contradictions and problems of chaotic environment in the reasoned, purposeful and productive way. It is a decision made using an approach that is fair, objective, and accurate based on information that is relevant to the situation. It is also defined as an ability to think clearly and rationally about what to do and believe including ability to engage in reflective and independent thinking. A critical thinker is able to: understand the logical connection between ideas, identify construct and evaluate arguments, detect inconsistence and common mistake and resuming, solve problem systemically, identify relevance and importance of idea, reflect on justification of one's own beliefs and value (Lau \& Cha 2014-2017).

During in-depth interviews respondents reported that practice critical thinking by reading guidelines, attend meetings, seeking information from people who are knowledgeable about maternal health issue, reporting, and seeking technical advice from different leant people. However, this does not indicate that there is practiced critical thinking. This may be among the limiting factors in implementation of maternal services.

\section{Competencies of a leader with respect to others}

This was viewed through five items namely: Communication, Negotiation, development other through teaching, developing other through mentoring. Findings were coded and came out with the following 
results in the graph no 2. Communication was highly ranked followed by developing others through teaching and mentoring. Negotiation and interdisciplinary team building were not mentioned at all as shown below.

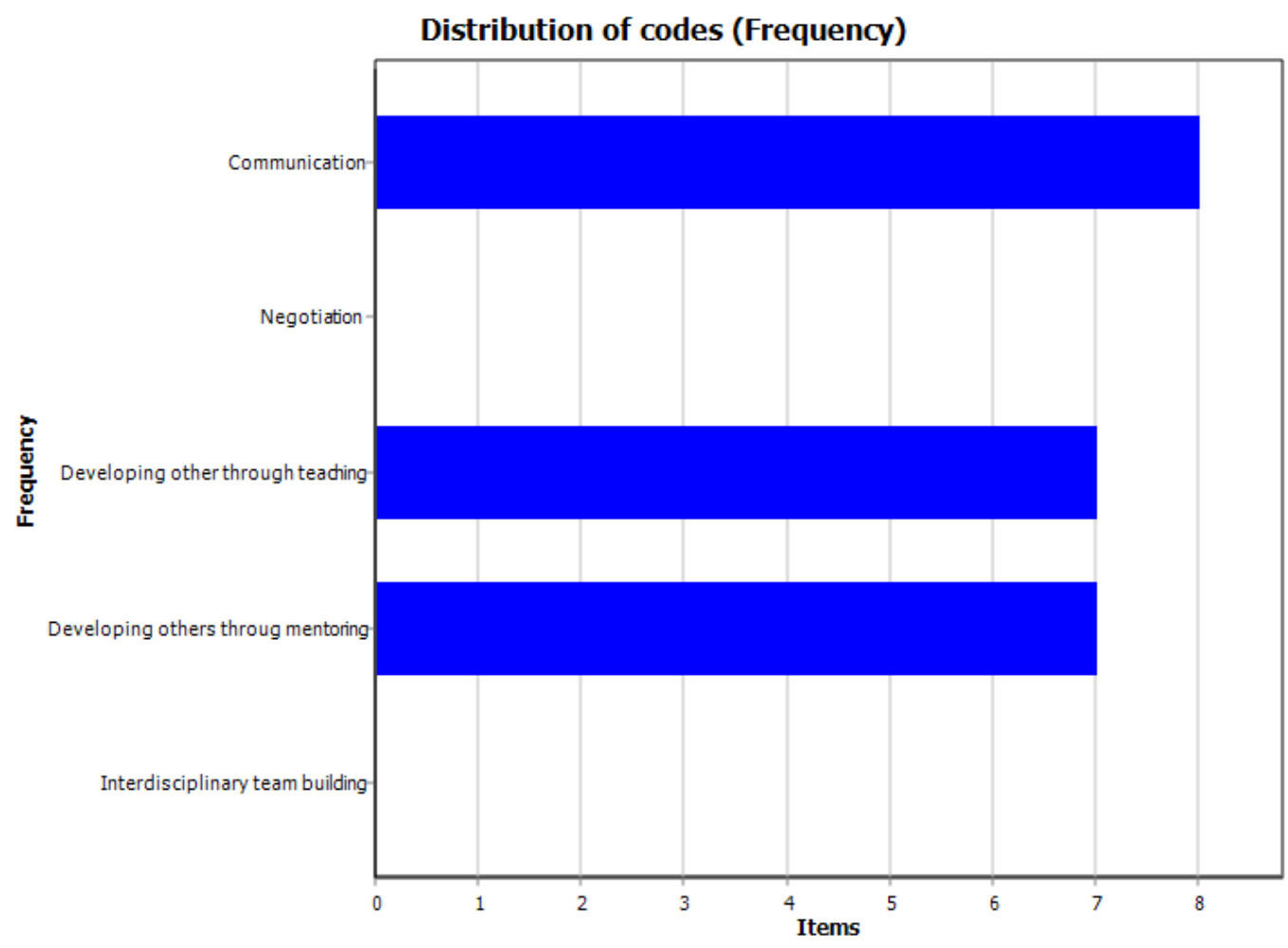

\section{Communication}

From analysis and coding communication was given a high priority in maternal health Competencies of a leader with respect to others. Most of respondents reported that extend leadership to co- workers by providing them with various guidelines, policies and supportive supervision. Moreover, it was said that junior staffs are tasked to provide educated on early booking to Anti-Natal Clinics, importance of health facility deliveries and breast feeding. Communication means were said to be through regular direct communication with District Medical Officers, meeting, continuous education, Council Health Management Team meetings, Community Health Workers meeting and stakeholders meetings. Respondent also mentioned, referrals, telecommunication availability of ambulance and Whatsapp, invitation letters and use local media. Finally, Face to face communication was given out by some of respondents that are taking place during monthly, quarterly supportive supervision visits and different gaps are addressed on spot.

"For instance during previous supportive supervision visit, we identified the problem of different staffs in the health facilities not filling the reporting forms as required and we worked on spot address this issue" (One of respondent)

It was further noted that communication have contributed a lot in addressing health problem particularly in reduction of maternal deaths in rural areas. Communication in maternal and child health is encouraged by various researchers and public health practitioners. For example: Nepal National Communication Strategy for Maternal, New born and child health (2011-2016); viewed that communication increase awareness on maternal health issues for both communities and services providers and there are relationships between maternal services seeking behaviors with partners' support, degree of communication with other women and health workers. 
DOI: $10.21522 / \mathrm{TIJPH} .2013 .05 .04 . A r t 044$

ISSN: $2520-3134$

\section{Developing others through teaching}

Developing others is enabling and coaches others constructively through reviewing their work in order to improve and advance their skills, knowledge and performance level of those who report to them. Teaching is defined as a concentrated sharing of knowledge and experience which usually is organized within a discipline and more generally the provision of stimulus to psychology and intellectual growth of personal by another person or artifact. Existence of developing others through teaching was revealed from respondents about how extent leadership to co- workers. It was noted that they provide them with various reports, guidelines and policies, through supportive supervision. $\mathrm{MCH}$, leadership competence group, 2009). This was said to be implemented during capacity building sessions such as training seminars and workshops, on job training, up grading course, whereby some are send back to schools "I am used to mentor, coach and conduct supportive supervision to them to bridge identified gaps and also hold periodical meetings whereby

"I orient and disseminate information to each other"

"It is done through trainings, joint supportive supervision, and mentoring to our fellow staff to ensure the implementation of policies:

"I do it through coaching and discussions in frequent meetings we hold" on job training, mentorship, and provision of needed information.

(Some of respondents during in-depth interviews)

\section{Developing others through mentoring}

Mentoring is a professional relationship in which a person (the mentor) assists other (the mentee) in developing specific skills and knowledge that enhance the less experienced person's professional. It can also be defined as a process whereby experienced highly regarded and empathetic person [mentor] guide another individual [mentee] in development of re-examination of their own ideas, learning and personal and professional development. Mentoring is a challenging task that requires flexibility, excellent communication and relationship building skills and ability to cope with rapid change of direction. In addition, this process requires various efforts such as change of knowledge and techniques which is different from a traditional supervision (Ndhlove, 2013). Mentoring program help professional to grow, develop and learn new skill under the direction and advice of seasoned expert. Organizations implementing mentoring align the goal of the company with professional development of its employee. This provides benefits for "mentee" mentor and organization (MCH, leadership competence group, 2009) In Maternal health services mentoring have been reported to contribute in the improvement of mother and child health. South Africa the study by University of California Los Angeles (UCLA) evidenced that community based mentorship intervention lead to better health outcome for both mothers and children.

Under this study, most of them pointed out that this is done through supportive supervision, regular follow mentorship and coaching of health care staff. It was also noted that Council Health Management Team (CHMT) provide directive and guidance to lower level staff and conduct joint supervisions and other stakeholders meetings.

"I am used to mentor, coach during supportive supervision to them to bridge identified gaps. We also hold periodical capacity building through trainings, joint supportive supervision, and mentoring the fellow staff to ensure the implementation of policies"

"I do it through coaching and discussions in frequent meetings we hold"

From these findings it can discussed that, though it was mentioned by respondents there are coaching and mentoring their fellows junior staff, in principal this is not actual mentoring or coaching as per Maternal and Child Health (MCH) Leadership Competencies Workgroup (2009). In order to cope with maternal health challenge, the group suggested that a leader in Maternal and Child $(\mathrm{MCH})$ requires specific, knowledge, skills, personal characteristics and values which are termed as leadership competence. The authors also noted that $\mathrm{MCH}$ leadership competence contains knowledge and skills required for core Conceptual framework which includes: framing of training and objectives for $\mathrm{MCH}$ leadership programme, measures and evaluation of leadership and training, cultivate, measure 
competences within the current MHC workforce and sustain the growth of $\mathrm{MCH}$ leadership throughout the care system.

Maternal Child Health leadership competence group (2009) also suggested 5 core areas which are vital for maternal leadership including successful political leadership, sound health policies, effective finance, sound health system and action to achieve equity. In consideration of the role that played by maternal health leaders in Kagera it seems that to some extent they lack capacity in mentoring and coaching order to ensure their effectiveness. This challenge was reported by The Ministry of Health and Social Welfare in Tanzania (2008) that factors for underutilization of maternal health system factors including inadequate monitoring, guidance.

\section{Interdisciplinary team building}

Team is a group of people or units organized to do a task together and "Interdisciplinary team" is a group of health care professionals from diverse field who work in a coordinated manner towards a common goal for the benefits of target groups such as patients and in our case maternal health target group. According to Maternal health and child health competence (2009), MCH systems are interdisciplinary in nature; it is a practice that provides a supportive environment in which the skills and expertise of team members from different disciplines, including families, are seen as essential and synergistic. The expertise of each team member is elicited and valued in making joint outcome-driven decisions to benefit individuals or groups in solving community or systemic problems.

The "team," which is the core of interdisciplinary practice, is characterized by mutual respect among disciplines and stakeholders, a sharing of leadership, investment in the team process, and acceptance of responsibility and accountability for outcomes. Members of an interdisciplinary team may include a variety of professionals, consumers, families, and community partners. This was one of the items which were not coded at all under competencies of a leader with respect to others. Advantages, usefulness and disadvantages of team work have been viewed by various development practitioner such as Crystal Vogl, Lisa McQuerrey \& Joseph in their articles (Undated) that it improve organizational effectiveness, shared knowledge, and faster result common purpose, group dynamic and manual spirits. Disadvantages includes unequal participation, not team players, limiting creativity, long process and inherent conflict as they were narrated by

Unfortunately, despite of this item being importance in maternal health promotion it was revealed from in-depth interviews. This does not mean that there are no health teams that are dealing with maternal health services such as RHMT, CHMT, WDCs and VDCs. In most cases these are formed routinely according to the Government guideline which may not be fitting the meaning and principles of interdisciplinary nature until

\section{Negotiation}

Negotiation is defined as a cooperative process whereby participants try to find out a solution that meets the legitimate interests of involved parties through discussion to provide agreement. $\mathrm{MCH}$ professional approaches the negotiation setting with objectively open to new information about awareness of long-term desired outcome that include relationship building and development of trust (MCH leadership competence, 2009). The Group on the importance of negotiation noted that during maternal health practices, people have different conflicting interest that require a leader or any members of maternal health force to address them in order to be successful. Findings from in-depth interviews revealed that negotiation was not mentioned as an important element during promotion of $\mathrm{MCH}$. This show weakness which exists in the implementation of services because some of our challenges need negotiation. This indicates that in Kagera region lack of negotiation capacity is among the gaps which are to be addressed in

Generally, it can be discussed that leadership with respect to others is an important element to underscore in maternal health and health system in general. This has been support by various researchers such as The Government of India (2014) reported success in MCH that strong Government leadership 
DOI: $10.21522 / \mathrm{TIJPH} .2013 .05 .04 . A r t 044$

ISSN: $2520-3134$

facilitated donor harmonization and design of simple tool, gap analysis which enabled rapid scale up of reproductive, maternal, newborn and child health and community awareness.

\section{Leadership competences with respect with wider community}

Working with community it is not working for community, it means that one has to learn how to work with community members. This is a way of Socializing with an unknown/ community rural. It is a process of learning something new from the community. It is about the customs and traditions and about its way of living Crybosk et al., 2006).

As this is a part of maternal health leadership competences; it should extends to a broader impact on entire organizations, systems, or general modes of practice. These wider areas of impact and influence require additional skills and a broader based understanding of the change process and the factors that influence change over time. This is done by $\mathrm{MCH}$ professionals in mobilizing communities to participate in the care and support of pregnant women or influencing health policies which support $\mathrm{MCH}$ services (MCH leadership competence, 2009).

This study investigated about maternal health leadership competences in relation to wider community. Coded items coded include working with community, working with system, policy adherence and policy advocacy. During Analysis working with community was leading for all four coded items followed by working with system thirdly policy adherence and lastly policy advocacy as per graph below. In the following section these items will discussed separately and about what are their implication under maternal health services.

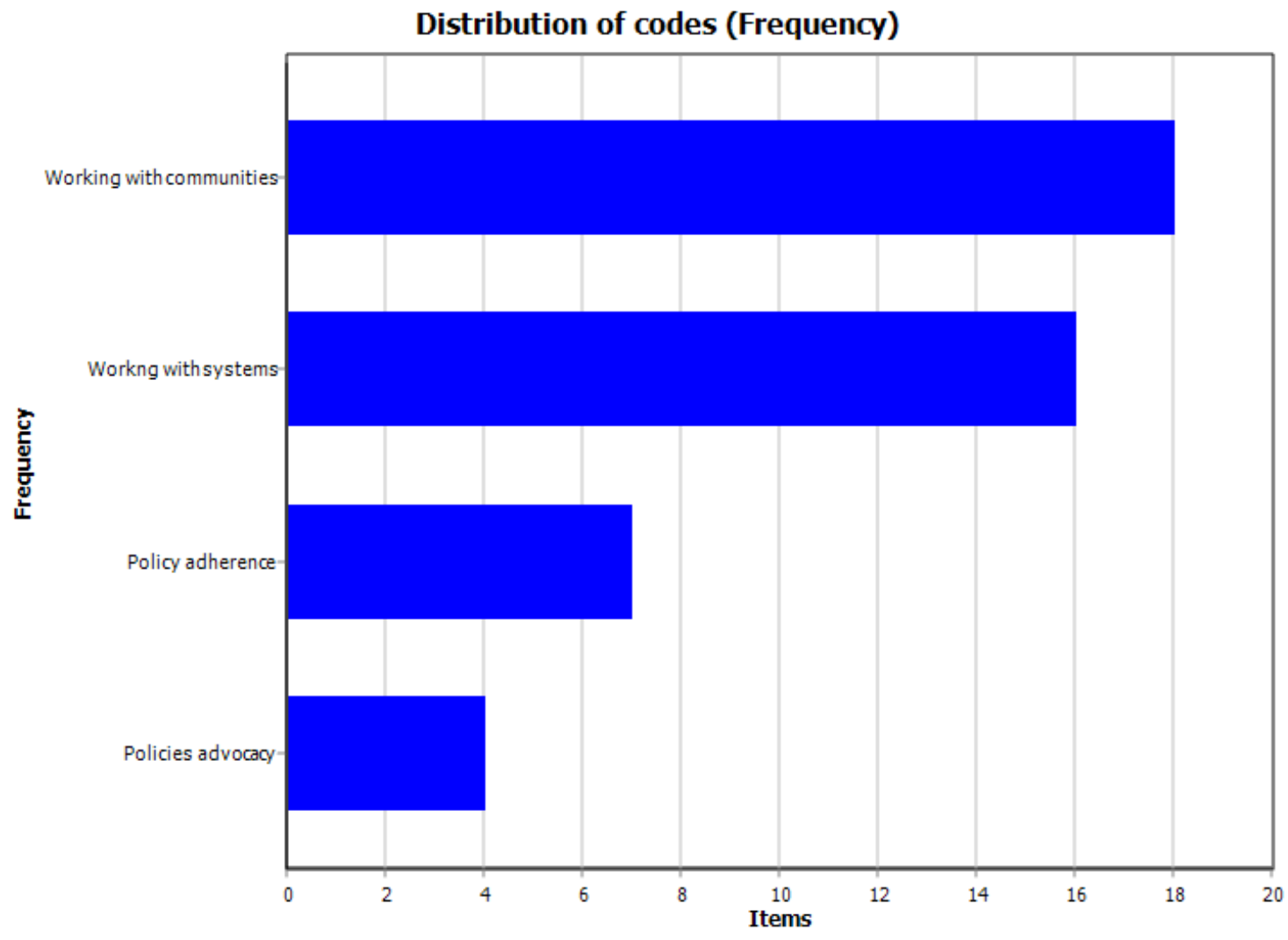

\section{Working with community}

Concerning working with community, in-depth interviews revealed various events which indicated that health workers work with communities. Respondents reported field visits for supportive supervision by Health Facilities staff and complemented by community Health Workers (CHWs) at community level. Moreover, it was noted that Council Health Management Team (CHMTs) work with community through 
health facilities by conducting data collection, analysis which is followed by review of data and thereafter discrepancies addressed accordingly. Some of respondents depicted that Community health workers are utilized in the community as a part of working with community whereby conduct education on important of Antenatal services such as early booking before 12 week of pregnancies and home visits.

Linkage between health facilities and families/ community respondent noted that they work closely Health facility Governing Commitees, Ward Development Committes (WDCs) and Village Development Committees (VDCs. It was also repeatedly expressed that various donors / health funding partners facilitate community maternal health services. Community leaders including Ward Executive Officers, Village Executive Officers, and community health committees were praised for their support in $\mathrm{MCH}$ community outreach services to remote areas/rural villages. Furthermore, community linkage systems were said to be doing well because of introduced Result Based Financing (RBF) project.

Under this project CHWs or any community based/traditions helper are given inceptive for escorting mothers to deliver in health facilities.

Community involvement in maternal health services were reported by respondents to be provided by community health workers who are trained in maternal health issues, community outreach, health and nutrition education. In addition, respondents mentioned that Village health committees provide support on maternal health services such as sensitization on early booking to ANC, Nutrition, HIV and Malaria prevention. Reasons for provision of these services were viewed by respondents to be enhanced by high level of understanding and education that exist among the leaders through regular trainings. Respondents were confident that community linkage is supported by community representatives through committees which are composed of people living in the location of the health facility, village development committee (VDC) and ward development committee (WDC). Some of respondents acknowledged that these committees have contributed in reduction of maternal deaths.

Above finding can be discussed that working with community in Kagera region is congruent with Primary Health Care (PHC) concept which advocated for essential health care that is practical, scientific and socially acceptable by the use of technologies that are universally acceptable, affordable include involvement, participation and self-determination (World Health Organization, 1978). From literature, these findings depict effects of leadership gaps that were earmarked to be factors for Primary Health Care failure. This was viewed by Werner (1995) that at local levels primary health care lacked community empowerment and equity aspects. This obstacle also faced Health Sector Reform it has been criticized that it lacked social participation and control through imposing user fee and vertical programme that cause reduction of health access to services including maternal health services for the needy families/ groups (Mujinja \& Kida, 014).This was further earmarked by the National audit Office of the Government of Tanzania (2011) that non health system factors which contribute on underutilization of maternal services. These were composed of inadequate community involvement and participation in planning, implementation and monitoring of health services, social cultural beliefs and practices, gender inequality, low health education and poor health care seeking behaviors.

\section{Working with systems}

Working with Systems is defined as an ability to appreciate complexity including the ability to understand the ways to interact them and influence outcomes (Maternal health leadership competence, 2009). In order to improve MCH services in the population, there is a need to pass through a process with difficult factors that influences maternal health. This is due to the fact that problems which face MCH sector are interlinked with various disciplines including array of public and private sectors which are supposed to work collaboratively. Therefore, to achieve goal and targets in $\mathrm{MCH}$, a leader requires wide scope based systemic approach rather than a single approach to the issue. The idea of systemic approach was supported by Maternal health leadership competences (2009) that a successful MCH leader should think systemically about the complex policy, practice, research and challenges including passion, persistence, self-motivation, optimisms, charisma, humanity and patience. 
DOI: $10.21522 / \mathrm{TIJPH} .2013 .05 .04 . A r t 044$

ISSN: $2520-3134$

Through in-depth interview it was reported by respondents that systemic approach is practiced through community linkage structures. These include Community based maternal health services providers such as village health workers and leaders like Ward Executive Officer, Village Executive Officer and village Government leaders with defined tasks. The role of community health workers include referring of pregnant mothers to health facilities, report maternal data, escorting referrals. It was further found out that every health facility is governed by committee whose members come from the community. These committees work closely with health facilities management in the provision of maternal health. It was further revealed that though Traditional helpers so called "Traditional Birth Attendants" have been discourage to attend home deliveries they are encouraged to accompany mothers when they approach them.

Additionally, it was found out that maternal health facilities reports are submitted to district authority every 5th date of the next month, the District Medical Officer reports to Regional Medical Office's on the 15th date of the coming month and the regions authority sample some centers for data verification. In addition, District Health Management Information System Version2 (DHMIS2) is used by districts and at regional level to ascertain achievement and failures by assessing number targeted groups of services.

Above finding indicate that Working with system is among the major components that underpin the universal accessibility and coverage of maternal health services. This mean the maternal health leaders should acknowledged that poverty, social unrest, instability, the environment, and lack of basic resources contribute to poor maternal health status (WHO, 1978). Failure in working with system as a part of maternal health leadership has been to be claimed to among the factors for underutilization of Maternal Health Services. This was demonstrated by WHO et al. (2014) in Bangladesh, Pakistan, Kenya, Nigeria and Tanzania that more than half of the births were delivered outside the formal health facilities due to low education levels among the women, high poverty among the families, and long distance to health facilities and lack of access and exposure to media. Furthermore, India, Singh et al. (2013) revealed that along with individual households and the community, district levels factors influenced low utilization of maternal health care services. Odds of maternal health care utilization were lower in rural areas and in communities with concentration of poor and illiterate women. In addition, these researchers highlighted on infrastructure such as unavailability of labor and registration rooms for pregnant mothers to be significantly influencing factors for the underuse of maternal services. In Additionally, Kagera Region RS \& RHMT (2015) earmarked poor infrastructures that complicated the situation of women to access comprehensive Emergency Obstetric and Neonatal Care (CEmONC).

\section{Policy adherence}

Definition: A policy is a decision designed to address a given problem or interrelated set of problems that affect a large number of people.

During in-depth interviews policy adherence was code number three in the above graph, most of respondents agreed that they are used to read Guidelines, nation policies, Standard Operating Procedure on maternal health. They further noted that maternal health is one of key priority and a major component under Comprehensive Council Health Plan and given a high priority even in budgetary share though district councils are not allocating maternal health.

"I am used to read policies, guidelines on family planning, PMTCT and national policies on maternal health service "(One of in-depth interviews respondents).

"I am used to read different means guidelines from Ministry of health and also reading different documents. This indicates that to some extent she used to be competent through reading and utilizing Government policies"

However, it can discuss that availability of policy and policy implementation or adherence to policies is two different issues. This is due to the fact that it was difficult to trace from interview about how responded ensure effectiveness of policies implementation. Which show that there are various policies which have been put in place to protect mothers of reproductive age and before, during pregnancies and during delivery but majority of them are not still receiving respective maternal health care. This was 
earmarked by Health policy Project team (undated) that while there are many interventions that aim to improve access to skilled health care, less attention has been focused on quality of such care, women are often encountering wide spread disrespect and abuse in facility based maternity care. The Ministry of Health and Social Welfare in Tanzania (2008) earmarked factors for underutilization of maternal health including unused pro-poor policies, poor health infrastructures, inadequate skilled health providers, unorganized referral systems, lack of equipment and supplies and weak managerial and coordination capacity.

\section{Policy advocacy}

Policy Advocacy consists of activities carried out on behalf of policies or constituencies; its purpose is to influence outcomes that affect peoples' lives. It is important for $\mathrm{MCH}$ leaders to possess policy and advocacy skills, because they often must defend and advocate for $\mathrm{MCH}$ resources in competitive economic and political environment, Policy advocacy was coded as the lastly scored item. This was not much pronounced from in-depth interviews though most of the respondents acknowledged that they ensure that junior staffs are able to educate mothers on ANC, early booking and important of health facility deliveries and breast feeding. This in real meaning does not indicate/ that there is policy advocacy but policy implementation. Moreover, since this only covers small potion health interdisciplinary team it may be among the factors which lead to underutilization of health policies.

Basing on these findings, discussion has been put forwards that these findings depict that policy in maternal health require a transformative leaders in order to be advocated. The same was suggesting by Lucy et al, (2014) \&Commissioner on Social Determinant of Health (2007) that Government actions for Public Accountability in health should pass through legislations on the rights of citizens to information and enabling them participate in public policy and budgeting. The authors also stressed on health equity in all policies, systems, programs on the rights of citizens to participate in health services deliveries including sexual, reproductive and maternal health.

\section{Conclusion}

The conclusion from these finding is that this is the study achieved her objective one on Determining the health system leadership capacity in management of maternal health care in Kagera region and Question to be answered of: What are capacities of maternal health leadership in order effect managing maternal health services?

It was revealed that respondents who are maternal health leaders possess and practice leadership competences in maternal health services through their routine duties including supportive supervision, staff meetings, mentoring and supportive supervision.

This means that leadership play a major role in the provision $\mathrm{MCH}$ as it was acknowledge by respondents under this thesis.

However, there was lack of understanding about what is the leadership capacity/competence in maternal health which may mean that they practice their competence by use of guidelines and principles.

Most of respondents noted the provision of directive and guidance to lower level staff and conduct joint supervisions and stakeholders meetings which are different from coaching and mentorship.

Moreover, maternal health teams are formed routinely according to the Government guideline which miss the meaning of interdisciplinary nature and lacked negotiation and policy advocacy practices which are important items under maternal health.

These to some extent may be contributing to some of gaps in $\mathrm{MCH}$ and contribute to maternal deaths

\section{Maternal health leadership awareness revealed}

i. The study revealed that respondents have leadership capacity and recognised the importance of strong leadership in maternal health 
DOI: $10.21522 / \mathrm{TIJPH} .2013 .05 .04 . A r t 044$

ISSN: $2520-3134$

ii. Coded items in self-competencies included: Professionalism, Ethic, Self-reflection, Critical thinking, developing others through teaching, Developing others through mentoring, Interdisciplinary team building and Negotiation

iii. Leadership competences for wider community revealed: Working with community, working with systems, Policy adherence and Policy advocacy

\section{Finding included}

- High level of understanding in working with community

- High level in understanding on policy adherence

- High level of understanding in working with system

- However it was observed that:

- Respondents lacked awareness and recognition of Ethic, Self-reflection, Critical thinking

- Were also less awareness on developing others through mentoring, interdisciplinary team building and Negotiation

\section{Recommendations}

Based on the findings and discussion the following are recommendations

i. There is a need to increase understanding about what is the leadership competence in maternal health

ii. More emphasis should be put on interdisciplinary ,negotiation and policy advocacy practices which are were not were recognized by respondents

iii.It is further recommended that even for items which were recognised by respondents such as working with community should be strengthened as they were not straight forwards.

iv. Gained Knowledge through this thesis could contribute towards improvement maternal health services in Kagera Region of Tanzania.

v. I would like to study specific how maternal health leaders rank themselves on their leadership role and how strength, weakness, opportunities and threat affect $\mathrm{MCH}$.

\section{References}

[1].Adrew. K. Shenton (2004) Strategies for Ensuring Trustworthiness in Qualitative Research Project: Division of Information and Communication Studies.

[2].Anders Anell, Anna H Glenngård, Sherry Merkur, (2012) Sweden Health system review Vol. 14 No. 5, Health Systems in Transition, European Observatory on Health System Policy.

[3].Association of Public health. On line available at: http://www.wpunj.edu/dotAsset/349325.pdf.

[4].Anuja Jayaraman1, S. Chandrasekhar \&Tesfayi Gebreselass, (2008).Factors Affecting Maternal Health Care Seeking Behavior in Rwanda.

[5].Christiana R Titaley, Michael J Dibley and Christine L Robert, (2007). Factors associated with underutilization of antenatal care services in Indonesia: results of Indonesia Demographic and Health Survey 2002/2003 and 2007

[6].Cindy Cartis, (2005).Devolving a Human Right Based Approach to address Maternal Mortality. DFID Health Research Centre, Desk review.

[7].Cresswell, J W \& Miller, D. L. (2000).Determining Validity in Qualitative Inquiry. Theory into Practice, 39 (3): $122-130$

[8].Daniel M. Jenkins \& Amanda B. Cutchens, (2011).Leading critically: A Grounded Theory of Applied Critical Thinking in Leadership Studies Journal of Leadership Education. Volume 10, Issue 2 - summer 2011. Ages New York: The Free Press: on line available: https://www.leadershipeducators.org/Resources/Documents/jole/2011_Summer/Jenkins\%20and\%20Cutchens.pdf [9].David Werner, (1993). The life and Death of Primary Health Care or the Mcdonaldization of Alma Ata. A talk by David Werner Seminar organized by: Medicine for the People Medical Aid for the Third World International People's Health Council. On line available: http://www.healthwrights.org/content/articles/Life_and_Death_of_PHC_Belgium.pdf 
[10]. Fagbamigbe F.A, (2015).Barriers to antenatal care use in Nigeria: evidences from non-users and implications for maternal health programming. Online available: https://www.k4health.org/sites/default/files/focused\%20antenatal\%20care_eng.pf $7 /$

[11]. Freddie Ssengooba, Stella Neema, Anthony Mbonye, Olive Sentubwe, Virgil Onama (undated) Maternal Health Review Uganda. Members of the Health Systems Development Programme, Makerere University Uganda.

[12]. Government of India, (2014). Indian's Reproductive, Maternal, New Born, Child health and Adolescent Health Strategy. A case of Extraordinary Government Leadership

[13]. Golafshan. N, (2003).Understanding Reliability and Validity in Qualitative Research, University of Toronto, Toronto, Ontario, Canada: online available at http://www.nova.edu/ssss/QR/QR8-4/golafshani.pdf

[14]. Glenn D. Israel and Sebastian Galindo-Gonzalez, (2014). Cooperative Extension Service, IFAS. University of Florida, Using Focus Group Interviews for Planning or Evaluating Extension Programs on line available at: http://edis.ifas.ufl.edu/pd036

[15]. Gupta S, Yamada G, Mpembeni R, Prudence G, Callaghan-Koru JA, Stevenson R, et al. (2014). Factors Associated with Four or More Antenatal Care Visits and Its Decline among Pregnant Women in Tanzania between 1999 and 2010. PLoSONE9(7):e101893.doi:10.1371/journal.pone.0101893:on line available on http://journals.plos.org/plosone/article?id=10.1371/journal.pone.0101893

[16]. Gupta S, Yamada G, Mpembeni R, Frumence G, Callaghan-Koru JA, Stevenson R, (2014). Factors Associated with Four or More Antenatal Care Visits and Its Decline among Pregnant Women in Tanzania between 1999 and 2010.

[17]. Informatic Lipman building, Northumria University New Castle upon Tyne, NEI 8ST.

[18]. UK. Education for information 22(2004) 63-75 IOS Press.

[19]. Kristina Crybosk, Nancy .V Yinger, Ricordo H. Dios, Heidi Worley, and Fariyal. F. Firee (2006). Working with Community for Improved health. Health Bullet .3 Washington DC Population reference Burue.

[20]. Krefting , L. (1991), Rigor in qualitative research , The Assessment of Trustworthiness, Qeens University, Kingston, Ontario, Canada. Kriasta Hawkins, Karen Newman, Deborah Thomas and Larisa Popovich, Elena Potapchik, Sergey Shishkin, Erica Richardson, Alexandra Vacroux and Benoit Mathivet, (2011). Health Systems in Transition, Russian Federation Health system review Vol. 13 No. 7 2011, European Observatory on health system policy.

[21]. Lau, J., \& Chan, J. (2004-2014). What Is Critical Thinking? On line available: http://www.oalib.com/references/14622148

[22]. Leslie Mancuso, Peter Johnson, Leah Hart and Kate Austin, (2015). Addressing Maternal and Newborn .A Leadership Perspective. Online available at: http://www.longwoods.com/content/24498

[23]. Liamputtong, P. R. \& Ezzy, D, (2005). Ch 3- Indepinterviews. In Qualitative Research Methods. Sydney: Oxford Univsersity Press: 54- 74.

[24]. Lucy Gilson, Judith Daire and Susan Clear, (2014). Developing leadership and management competencies in low and middle-income country health systems: a review of the literature. Working Paper 4, Health Economics Unit University of Cape Town. South Africa: Available on line: http://r4d.dfid.gov.uk/pdf/outputs/ReSyst/WP4_resyst.pdf

[25]. Marcos Cuet (undated) The Origins of Primary Health Care and Selective Primary Health Care. Selective Primary Health Care. Universidad Peruana Cayetano Heredia. Online Available: http://www.who.int/kms/initiatives/ghhcueto.pdf

[26]. MCH Leadership Competencies Workgroup, (2009). Maternal and Child Health Leadership Competencies VERSION 3.0. On line available at: http://devleadership.mchtraining.net/mchlc_docs/mch_leadership_comp_3$0 . p d f$

[27]. Morth Ndhlovu, (2013). The role of intensive mentorship in EmONC in improved Quality of Care, The NCHIP approach in Mansa Zambia save mother giving life

[28]. Nankwanga A, (2004).Factors influencing utilisation of postnatal services in Mulago and Mengohospitalskampala, Uganda. Minthesis submitted in partial fulfilment of the requirements for the degree of Master of Science Physiotherapy in the Department of Physiotherapy, University of the Western Cape. 
DOI: $10.21522 / \mathrm{TIJPH} .2013 .05 .04 . A r t 044$

ISSN: $2520-3134$

[29]. Nepal National Communication Strategy for Maternal, Newborn and Child Health, (2011-16). on line available http://scalingupnutrition.org/wp-content/uploads/2012/09/Nepa-National-Communications-Strategy-on-MNCH-

2011-2016_en.pdf

[30]. OrnellaLincetto, SeipatiMothebesoane-Anoh, Patricia Gomez, Stephen Munjanja. Antenatal Care (undated) Opportunities for Africa's Newborns Chapter 2

[31]. Patton, M. (1990). Qualitative Evaluation and Research Methods (pp. 169-186) Beverly Hells CA; Sage

[32]. Prashant Kumar Singh, Chandan Kumar, Rajesh Kumar Rai and Lucky Singh,(2013). Factors associated with maternal healthcare services utilization in nine high focus states in India: A multilevel analysis based on 14385 communities in 292 districts.

[33]. Priscilla Rivas-Loría \& Caroline Shelto, (2004).analysis of health sector reforms region of the Americas. Strategic Health Development Area at PAHO/WHO, Washington D.C.

[34]. Rhoune Ochako, Jean-Christophe Fotso, Lawrence Ikamari, and Anne Khasakhala, (2003).Utilization of maternal health services among young women in Kenya: Insights from the Kenya Demographic and Health Survey [35]. Simon, M. K. (2011). Validity and Reliability in Qualitative Studies Excerpted from Dissertation and scholarly research: Recipes for success (2011 Ed.). Seattle, WA, Dissertation Success, LLC on line available at: http://dissertationrecipes.com/wp-content/uploads/2011/04/Validity-and-Reliability-in-a-Qualitative-Study.pdf

[36]. The Government of TZ (2014) Tanzania Big Results Now Health Care Lab. On line available at: http://www.tzdpg.or.tz/fileadmin/documents/dpg_internal/dpg_working_groups_clusters/cluster_2/health/Sub_Secto r_Group/BRN_documents/Tanz_Healthcare_Lab_Report_Part_1_0212_RH_-_v21_Final_Lab_Report_.pdf

[37]. The Government of Rwanda Ministry of health, (2013). Maternal, neonatal and child health national strategy 2013- 2018: online available at: www.moh.gov.rw

[38]. The Partnership for Maternal, Newborn and Child Health, (2008). Successful leadership country actions for maternal, Newborn and Child Health

[39]. The United republic of Tanzania (2015) .The prime minister's office Regional Administration and Local Government. Action plan to accelerate the reduction of maternal, newborn and child deaths 2014 - 2015. Kagera region sharpened one plan, Regional Commissioner's Office, Health Department P.O Box 265, and Kagera Phone: 028-2220351 Fax No: 028-2221425 E-mailrhmtkagera@googlegroups.com

[40]. The united republic of Tanzania, (2011).A performance audit on the monitoring, Evaluations and budget allocation for maternal health care activities in Tanzania. Ministry of health and social welfare a report of the controller

[41]. The United republic of Tanzania, (2003).MOHSW Second Health Sector Reform strategic Plan.

[42]. The united republic of Tanzania, (2015) .The prime minister's office Regional Administration and Local Government. Action plan to accelerate the reduction of maternal, newborn and child deaths $2014-2015$.

[43]. The united republic of Tanzania, (2015). RHMT annual plan 2015-2016, KAGERA .Regional Commissioner's Office, Health Department

[44]. United Republic of Tanzania Ministry of Health and Social Welfare (2008).The National Road Map Strategic Plan To Accelerate Reduction of Maternal, Newborn and Child Deaths in Tanzania 2008 - 2015

[45]. United Republic of Tanzania Ministry of Health and Social Welfare, (2008). The National Road Map Strategic Plan to Accelerate Reduction of Maternal, Newborn and Child Deaths in Tanzania 2008 - 2015

[46]. UCLA, (2014). South African Mentor Mother improves Perinatal Health Outcome.

[47]. Online available at: http://newsroom.ucla.edu/releases/south-african-mentor-mothers-program-improvesperinatal-health-outcomes

[48]. Victorian Maternal and Child health Services, (2009). Maternal and Child Health Service: Practice Guidelines On line available.

[49]. http://www.education.vic.gov.au/Documents/childhood/professionals/health/mchpracticeguidelines.pdf

[50]. WHO, (2008).Social Determinant of Health Report. Closing the gap in a generation, health equity though

action on social determinant of health. Online available

http://www.who.int/social_determinants/thecommission/finalreport/en/

[51]. World Health Organization, (1978). Primary Health Care, Report of International Conference on Primary Health Care, Alma Ata, USSR, 6-12 September 1978: 43-48. 
Texila International Journal of Public Health Volume 5, Issue 4, Dec 2017

[52]. WHO, (2015) Health in 2015: from MDGs to SDGs, Monitoring Health for the SDGs. WHO: Geneva. On line available: http://www.whoint/gho/publication/mdg/en/ 